\title{
FALHAS DE MANEJO NA FASE DE ENGORDA DE TILÁPIAS E SUA RELAÇÃO COM A DISPARIDADE DE PESO FINAL
}

\author{
Danieli Dal Bosco Quadros* \\ Julio Daniel do Vale*
}

\begin{abstract}
RESUM0: 0 presente estudo foi realizado na região Oeste do Paraná, considerada 0 polo agropecuário da produção de peixes do Estado, região que concentra 17 frigoríficos de abate e industrialização de pescados, tem como objetivo informar o produtor em relação à engorda do lote, bem como sobre as análises da qualidade da água do viveiro com 0 intuito de verificar as falhas de manejo que contribuem para a disparidade de tamanho final dos peixes. Durante cinco meses (out/18 a fev/19) foram monitorados seis viveiros em quatro pequenas propriedades localizadas no município de Toledo-PR. Para a biometria foram utilizadas amostragens com 50 indivíduos por viveiro, pesados e medidos individualmente. A disparidade de peso foi calculada utilizando-se 0 desvio padrão amostral de cada lote. A sonda multiparâmetros foi utilizada para mensurar: temperatura, $\mathrm{pH}$, condutividade elétrica, sólidos totais dissolvidos, oxigênio dissolvido e turbidez. Os resultados demonstraram forte correlação entre turbidez, sólidos totais dissolvidos e condutividade elétrica com a disparidade de tamanho das tilápias. Foi observado superlotação dos viveiros. 0 desvio padrão de peso aumentou à medida que os peixes cresceram. Conclui-se que a qualidade da água afeta diretamente 0 desenvolvimento dos peixes e a falta de manejo adequado deste ambiente, contribui para com o aumento da disparidade de peso e tamanho das tilápias.
\end{abstract}

PALAVRAS-CHAVE: Biometria; Parâmetros limnológicos; Piscicultura; Qualidade da água.

\section{FAULTS IN MANAGEMENT IN THE FATTENING PHASE OF TILAPIA AND ITS RELATIONSHIP WITH DIFFERENCE IN FINISH WEIGHT}

\begin{abstract}
Current analysis was undertaken in the western region of the state of Paraná, Brazil, an agrostockbreeding reference center in fish production, characterized by 17 fish abattoirs and industries. The study informs the producer on fattening of fish lots and analysis of ponds' water quality to verify faults in management that contribute towards the difference in fish finishing size. Six ponds in four small farms in the municipality of Toledo PR Brazil were monitored during five months (October 2018 - February 2019). Samples with 50 specimens per pond were used for biometry, weighed and measured individually. Weight difference was calculated by sample standard deviation of each lot. Multiparameter probe measured temperature, $\mathrm{pH}$, electric conductivity, dissolved total solids, dissolved oxygen and turbidity. Results showed strong relationship between turbidity, total dissolved solids and electric conductivity and difference in tilapia size. Over population in the ponds was also detected. Standard deviation of weight increased according to fish growth. Results show that water quality directly affects the development of fish and lack of proper management contributes towards an increase in differences in tilapia weight and size.
\end{abstract}

KEYWORDS: Biometry; Limnological parameters; Pisciculture; Water quality.

\footnotetext{
*Graduanda do $10^{\circ}$ período de Medicina Veterinária pela Pontifícia Universidade Católica do Paraná (PUCPR), Toledo, Paraná, Brasil. E-mail: daniely-07@hotmail.com

${ }^{* *}$ Doutorado em Ecologia pelo Instituto Nacional de Pesquisas da Amazônia (INPA). Docente no departamento de Ciências Biológicas na Pontifícia Universidade Católica do Paraná (PUCPR), Toledo, Paraná, Brasil.
} 


\section{INTRODUÇÃo}

A tilápia do Nilo é a espécie mais criada na piscicultura brasileira e o segundo grupo de peixes mais produzidos no mundo. Segundo 0 anuário da Peixe BR (2019), o Brasil produziu 400.280 toneladas de tilápia em 2018, representando $55,4 \%$ da produção total de peixes de cultivo, mantendo a quarta posição mundial de tilápias. 0 Estado do Paraná ocupa o primeiro lugar na produção de tilápias com 123 mil toneladas, e na região Oeste do Paraná concentram-se $69 \%$ desta produção, de acordo com o DERAL - Departamento de Economia Rural (PEIXE BR, 2019).

A região Oeste do Paraná é propícia para a piscicultura, pois apresenta elevada capacidade de produção da matéria-prima (pescado), alta oferta de matéria-prima, topografia e clima favorável à construção de viveiros, empresas para o processamento do pescado, mercado promissor com 0 aumento do consumo per capita. Tais peculiaridades desta região a caracterizam como sendo o polo produtivo do Estado (CHIDICHIMA, 2014).

Esses aspectos favoráveis da região fazem com que a piscicultura cresça rapidamente, surgindo a preocupação com mão de obra qualificada. Essa produção intensiva de tilápias se manejada incorretamente causará severas disparidades no lote, em função de peso e tamanho. Uma boa prática para minimizar esta disparidade é 0 acompanhamento biométrico, sendo essencial para estimar 0 crescimento mensal dos peixes, auxiliando o produtor na identificação de erros de manejo que causam a diferença de tamanho dentro de um mesmo viveiro de peixes e estimar 0 tempo de cultivo (OLIVEIRA et al., 2007).

0 manejo mais utilizado para a engorda da tilápia em viveiro escavado, geralmente, ocorre em fase única, quando os alevinos são engordados até obterem peso de venda comercial, variando de 800 a 1.000 gramas (KUBITZA, 2009). 0 ganho em peso em animais saudáveis reflete 0 crescimento e pode ser acompanhado pelas variáveis de comprimento, altura, largura, ao invés do tempo, desconsiderando assim, variações extrínsecas ao indivíduo que interferem na relação entre peso e idade (SANTOS, 2004).

Preconizando-se 0 acelerado desenvolvimento das tilápias, 0 acompanhamento das características físicas, químicas e biológicas de viveiros voltados à produção de organismos aquáticos contribui para a manutenção de níveis adequados de qualidade da água, gerando a expansão e 0 sucesso econômico desta atividade (LIMA et al., 2013; SIPAÚBA TAVARES, 1994).

Furuya (2007) afirma que boas práticas de manejo interferem diretamente na qualidade da água, pois a subalimentação dos peixes piora o desempenho do lote sem comprometer a qualidade da água, enquanto 0 excesso pode comprometer o desempenho de forma direta, piorando a conversão alimentar e, indiretamente, na redução da qualidade da água.

0 presente estudo teve como objetivo avaliar 0 desenvolvimento de tilápias na fase de engorda $e$ relacionar esse crescimento com dados da qualidade da água, com o intuito de verificar as falhas de manejo que contribuem para a disparidade de peso e tamanho final do lote.

\section{METODOLOGIA}

0 projeto foi realizado em quatro propriedades particulares de piscicultores, localizados no município de Toledo - PR. Os locais de amostragem foram identificados pelos números (1,2,3,4,5 e 6), totalizando seis viveiros. A pesquisa envolveu apenas a espécie tilápia, criada em viveiros escavados e teve duração de cinco meses (outubro de 2018 a fevereiro de 2019).

Os aspectos gerais de cada viveiro podem ser visualizados na Tabela 1. Em cada coleta mensal foram realizadas amostras padrões de 50 tilápias por viveiro. Os peixes foram capturados com 0 auxílio de uma tarrafa e então colocados em baldes plásticos com 20 litros de água do próprio viveiro, após serem pesados em balança digital e, medidos com uma trena, eram soltos imediatamente. A disparidade de peso foi calculada pelo desvio padrão amostral de cada lote. As biometrias foram realizadas uma vez por mês durante cinco meses consecutivos. 
No local de amostragem 2, a biometria foi encerrada no mês de janeiro quando as tilápias atingiram peso de venda comercial e foram entregues ao frigorífico. Nos outros locais, os lotes foram entregues no mês de fevereiro de 2019, encerrando o acompanhamento biométrico. Apenas um lote não foi entregue ao frigorífico, pois o peso médio dos peixes ainda não havia chegado no peso comercial aceito pelos frigoríficos até o final das coletas de dados do presente estudo.

Tabela 1. Informações gerais sobre os seis viveiros de tilápias monitorados no município de Toledo - PR durante o período de outubro de 2018 a fevereiro de 2019.

\begin{tabular}{|c|c|c|c|c|c|c|c|}
\hline $\begin{array}{c}\text { Viveiros } \\
\text { monitorados }\end{array}$ & $\begin{array}{l}\text { Tamanho do } \\
\text { açude }\left(\mathbf{m}^{2}\right)\end{array}$ & $\begin{array}{l}\text { Quantidade } \\
\text { peixes } \\
\text { alocados }\end{array}$ & $\begin{array}{c}\text { Densidade } \\
\left(\mathbf{m}^{2}\right)\end{array}$ & $\begin{array}{c}\text { Idade } \\
\text { inicial } \\
\text { (meses) }\end{array}$ & $\begin{array}{c}\text { Idade } \\
\text { final } \\
\text { (meses) }\end{array}$ & $\begin{array}{c}\text { Peso } \\
\text { médio final } \\
\text { (gramas) }\end{array}$ & $\begin{array}{l}\text { Tamanho } \\
\text { médio final } \\
\text { (cm) }\end{array}$ \\
\hline 1 & 6.700 & 66.000 & 9,8 & 6 & 11 & 718 & 31,7 \\
\hline 2 & 12.000 & 50.000 & 4,1 & 11 & 15 & 821 & 34,3 \\
\hline 3 & 468 & 1.500 & 3,2 & 11 & 16 & 851 & 35,0 \\
\hline *4 & 300 & 1.200 & 4,0 & 7 & - & 513 & 29,2 \\
\hline 5 & 910 & 8.000 & 8,7 & 7 & 12 & 883 & 34,3 \\
\hline 6 & 630 & 3.000 & 4,7 & 7 & 12 & 875 & 33,4 \\
\hline
\end{tabular}

${ }^{\star} 0$ lote 4 amostrado não foi entregue ao frigorífico até 0 final do período de monitoramento Fonte: Os autores (2019).

A análise da água dos viveiros iniciou no mês de novembro, sendo realizada concomitante as biometrias mensais. Para mensuração dos parâmetros físicos e químicos da água, foi utilizada a sonda multiparâmetros Hanna Instruments ${ }^{\circledR}$ (HI9829). A leitura dos parâmetros limnológicos era realizada próxima a saída da água, em uma profundidade de $\mathbf{4 0}$ $\mathrm{cm}$. Os parâmetros mensurados foram temperatura, pH (diferença de variação de pH), CE (condutividade elétrica) - S/cm, TDS (sólidos totais dissolvidos) - ppm, O.D. (oxigênio dissolvido) - ppm e turbidez - FNU.

A pesquisa teve aprovação do Comitê de Ética no Uso de Animais - CEUA da PUCPR (protocolo $n^{\circ}$ 01269).

\section{RESULTADOS}

0 desvio padrão do peso evidenciou que há uma variação entre os lotes amostrados e que, embora eles tenham valores maiores nos últimos meses, já desde a primeira amostragem, os viveiros 2, 3 e 4 apresentaram grande disparidade no peso dos indivíduos $(171,150,138 \mathrm{~g}$ respectivamente) (Figura 1).

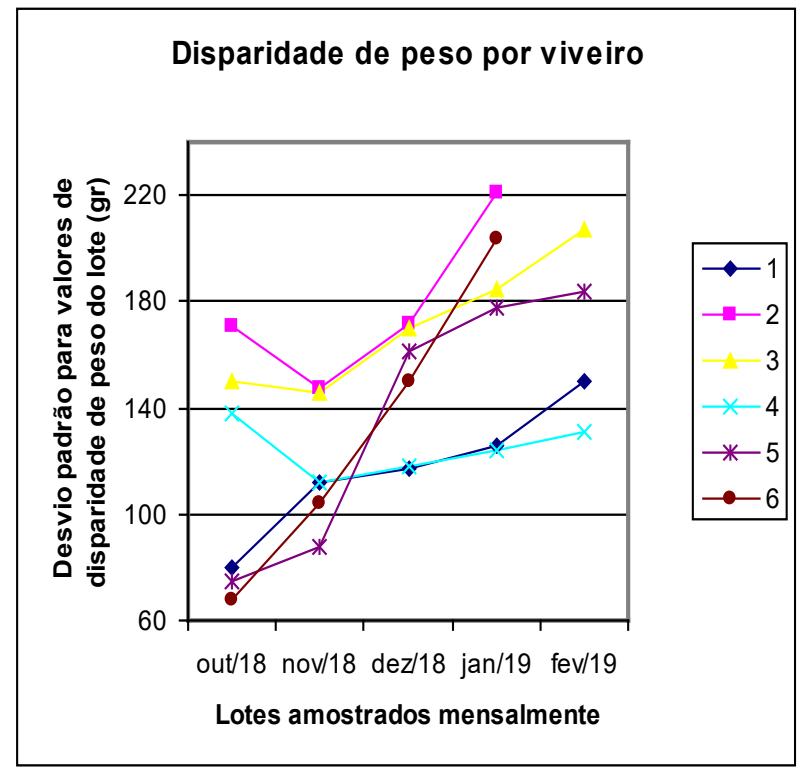

Figura 1. Disparidade entre o peso dos indivíduos de cada viveiro, expressa pelo valor do desvio padrão em gramas das tilápias, comparando os dados de cada local de amostragem entre os meses de outubro de 2018 a fevereiro de 2019.

Fonte: Os autores (2019). 
Na Tabela 2, é possível verificar que o pH se manteve dentro do recomendado durante todo o período de estudo. A temperatura teve pouca variação ao decorrer dos meses, somente no local de amostragem 5 no mês de fevereiro, esteve poucos graus abaixo do indicado na literatura. 0 oxigênio dissolvido foi o parâmetro de maior preocupação, estando maior parte do tempo com valores inferiores ao limite mínimo indicado para piscicultura. Para valores de turbidez evidenciou-se significativa diferença entre os viveiros amostrados, na maioria deles 0 valor médio encontrou-se acima do recomendado. No geral, os sólidos totais dissolvidos estiveram em algum momento acima do valor limite sugerido (04 dos 06 viveiros). No caso da condutividade elétrica, notou-se que três viveiros apresentavam valores adequados, dois viveiros com valores acima e um viveiro com valor abaixo do ideal.

Tabela 2. Valores médios e intervalos (mínimos e máximos) dos principais parâmetros limnológicos obtidos nos 06 viveiros monitorados, no período entre novembro de 2018 a fevereiro de 2019

PARÂMETROS MONITORADOS

\begin{tabular}{|c|c|c|c|c|c|c|}
\hline \multirow{2}{*}{ VIVEIROS } & \multirow{2}{*}{ PH } & \multirow{2}{*}{ TEMPERATURA $\left({ }^{\circ} \mathrm{C}\right)$} & $0 . D$ & TURBIDEZ & TDS & C.E \\
\hline & & & (PPM) & (FNU) & (PPM) & $(\mu \mathrm{S} / \mathrm{CM})$ \\
\hline \multirow{2}{*}{1} & 6,6 & 28,1 & $\underline{2,8}$ & $\underline{59}$ & $\underline{46}$ & $\underline{97}$ \\
\hline & $(6,2-6,7)$ & $(27,5-29,1)$ & $(0,3-7,9)$ & $(48-76)$ & $(36-58)$ & $(77-122)$ \\
\hline \multirow{2}{*}{2} & 6,7 & 29,4 & $\underline{2,9}$ & 45 & $\underline{31}$ & 67 \\
\hline & $(6,5-7,3)$ & $(29,2-29,5)$ & $(1,6-3,7)$ & $(40-48)$ & $(23-38)$ & $(50-82)$ \\
\hline \multirow{2}{*}{3} & 7,2 & 27,8 & 4,3 & $\underline{95}$ & 16 & 32 \\
\hline & $(6,7-8,5)$ & $(27,0-29,0)$ & $(0,4-11,0)$ & $(34-179)$ & $(3-23)$ & $(6-47)$ \\
\hline \multirow{2}{*}{4} & 6,7 & 29,0 & 4,3 & $\underline{98}$ & 21 & 44 \\
\hline & $(6,4-6,9)$ & $(28,0-29,8)$ & $(0,4-10,9)$ & $(63-124)$ & $(17-24)$ & $(37-52)$ \\
\hline \multirow{2}{*}{5} & 6,9 & 28,1 & $\underline{1,3}$ & $\underline{128}$ & $\underline{25}$ & 52 \\
\hline & $(6,0-8,1)$ & $(26,4-29,9)$ & $(0-4,4)$ & $(113-155)$ & $(15-34)$ & $(34-69)$ \\
\hline \multirow{2}{*}{6} & 6,6 & 28,1 & 1,8 & 34 & 22 & 47 \\
\hline & $(6,2-7,0)$ & $(27,4-29,2)$ & $(0-4,7)$ & $(20-58)$ & $(13-28)$ & $(28-58)$ \\
\hline Recomendado & $6,0-8,5$ & $27,0-32,0$ & $>4$ & $25-50$ & $<25$ & $23-71$ \\
\hline
\end{tabular}

Fonte: Os autores (2019).

Na Tabela 2, os valores médios abaixo ou acima do recomendado para piscicultura estão sublinhados na tabela e destacados em negrito ao final (referências para determinação dos valores recomendados de pH e temperatura (KUBITZA, KUBITZA, 2000); oxigênio dissolvido (PEREIRA, SILVA, 2012); turbidez (QUEIROZ, SILVEIRA, 2006); sólidos totais dissolvidos (TIMMONS et al., 2002); condutividade elétrica (SIPAÙBA-TAVARES, 1994).

De acordo com o Teste de Correlação de Pearson (Tabela 3), algumas variáveis ambientais exibiram maior 
relação com a disparidade de peso e tamanho das tilápias monitoradas. 0 pH apresentou correlação para a disparidade de peso e tamanho. A turbidez, sólidos totais dissolvidos e condutividade elétrica denotaram correlação para a disparidade de tamanho.

Tabela 3. Teste de Correlação de Pearson entre as médias das variáveis limnológicas ( $\mathrm{pH}$, temperatura, 0.D., turbidez, TDS e C.E.) e a disparidade final (de peso e tamanho) dos lotes de tilápias monitorados durante 0 estudo

\begin{tabular}{ccccc} 
& \multicolumn{2}{c}{ POR PESO } & \multicolumn{2}{c}{ POR TAMAMNHO } \\
\cline { 2 - 5 } Variável & $\mathbf{R}^{2}$ & $\boldsymbol{P}$ & $\mathbf{R}^{2}$ & $\boldsymbol{P}$ \\
\hline $\mathrm{pH}$ & $-0,093$ & 0,673 & $-0,057$ & 0,794 \\
Temperatura & 0,257 & 0,236 & $-0,341$ & 0,110 \\
0.D. & $-0,172$ & 0,431 & $-0,252$ & 0,244 \\
Turbidez & 0,205 & 0,346 & 0,026 & 0,905 \\
TDS & $-0,240$ & 0,268 & $-0,037$ & 0,864 \\
C.E. & $-0,226$ & 0,299 & $-0,049$ & 0,820 \\
\hline Fonte: 0s autores (2019). & & &
\end{tabular}

Fonte: Os autores (2019)

\section{DISCUSSÃo}

Na região Oeste do Paraná, a criação de tilápias geralmente acontece em sistema semi-intensivo em viveiros escavados, com área média de $10.000 \mathrm{~m}^{2}$ para terminação dos peixes e densidade de 2,5 peixes/ $\mathrm{m}^{2}$ (HEIN et al., 2004). 0 local de amostragem que mais se aproximou em relação ao tamanho médio dos viveiros, foi 0 viveiro 2. E quanto a densidade média recomendada, 0 mais próximo seria o viveiro 3 (Tabela 1). 0 autor citado relata que produtores desta mesma região acompanhados pela EMATER-PR obtiveram valores produtivos crescentes com densidade entre 2,5 a 3,89 peixes $/ \mathrm{m}^{2}$. Já Marengoni et al (2008) afirmam que três peixes $/ \mathrm{m}^{3}$ neste mesmo sistema sem taxa de renovação de água, apresenta maior produtividade $\mathrm{e}$ lucro ao produtor, pois densidade de quatro peixes $/ \mathrm{m}^{3}$ apresentam efeitos negativos, pelo excessivo consumo de ração e a menor biomassa.

Os peixes maiores tendem a se tornar dominantes, garantindo acesso as melhores condições (alimento, locais de reprodução), enquanto os peixes menores (submissos) acessam pequena parte dos recursos (BALDISSEROTTO, 2013). Isto faz com que haja um desequilíbrio alimentar no ambiente aquático, em que as necessidades energéticas de alguns indivíduos não sejam supridas, enquanto outros peixes receberão superalimentação. Consequentemente, haverá peixes com mesma idade e diferentes pesos $\mathrm{e}$ tamanhos no mesmo lote. Embora tenha variado entre os locais de amostragem, esse efeito foi observado nesse estudo, e conforme o previsto, foi acumulativo. Para minimizar tal disputa, 0 ideal seria considerar a densidade de peixes $/ \mathrm{m}^{2}$, além de fornecer a ração em diversos pontos ao decorrer do viveiro.

De acordo com a Tabela 2, é possível observar que os valores mínimos e máximos de pH mensurados nos viveiros amostrados estiveram dentro do esperado 6,0-8,5 (RODRIGUES, 1995; KUBITZA; KUBITZA, 2000; CONAMA, 2005). Pode-se afirmar que estes valores próximos à neutralidade são benéficos para 0 desenvolvimento das tilápias, pois mantém níveis compatíveis com a sobrevivência dos peixes. Mata et al (2018) afirmam a criação de tilápias em viveiros escavados é benéfica pelo poder tampão sobre $0 \mathrm{pH}$. 0 efeito tampão regula 0 nível de gás carbônico nos viveiros, pela da sua retirada por meio da fotossíntese, propiciando elevação do pH do ambiente aquático. Níveis elevados de gás carbônico na água, acima de 20 $\mathrm{mg} / \mathrm{L}$, causam asfixia nos peixes (KUBITZA, 2017). De acordo com Kubitza (2017), o resultado de dois estudos realizados sobre 0 efeito do $\mathrm{pH}$ no desempenho da tilápia do Nilo, o estudo realizado no Egito, apresentou melhores resultados no ganho de peso dos peixes mantidos em água de pH 7,0 ou 8,0, comparado a peixes mantidos em água de $\mathrm{pH} 6,0$ ou 9,0. Já 0 estudo conduzido no Brasil mostrou a boa adaptação das tilápias em águas ácidas (4 a 6) com ganho de peso e conversão alimentar superior ao dos peixes mantidos em pH 8,0.

A temperatura da água também teve pouca variação entre os meses de novembro a fevereiro, somente no local de amostragem 5 foi registrado 
temperatura inferior à indicada por Kubitza (2000) de 27 a $32^{\circ} \mathrm{C}$, condizendo com 0 mês de fevereiro, em que havia chovido no dia anterior à biometria e houve decréscimo na temperatura $\left(26,4^{\circ} \mathrm{C}\right)$. Porém, os autores Hein e Brianese (2004) afirmam que a temperatura entre 26 a $28^{\circ} \mathrm{C}$ é favorável para 0 desenvolvimento das tilápias, estando o local de amostragem 5 dentro da normalidade segundo os autores citados acima. De acordo com Jauncey (1982), a temperatura da água na faixa de $30^{\circ} \mathrm{C}$ é a que possibilita 0 máximo desenvolvimento e a melhor eficiência metabólica em tilápias. Esta informação apresentada, difere dos resultados encontrados nesta pesquisa, em que o local de amostragem 2, o que manteve a temperatura média em $29,4^{\circ} \mathrm{C}$ ao longo dos quatro meses, foi 0 segundo lote que mais demorou para atingir peso de venda comercial, com 15 meses. Além do tamanho médio final do lote 2 ser 0 mesmo do lote amostrado 5, este último alcançou respectivo tamanho aos 12 meses de idade, com peso médio final superior aos demais lotes (Tabela 2). Estando a temperatura adequada em todos os lotes amostrados, supõe-se que outro parâmetro limnológico da água possa ter influenciado neste atraso de desenvolvimento.

Observando-se o parâmetro limnológico de mais importância na piscicultura (LIMA et al., 2013), foi constatado que os níveis de oxigênio dissolvido estiveram insuficientes em todos os produtores em algum momento da produção, chegando a 0,0 $\mathrm{mg} / \mathrm{l}$ (Tabela 2). Como os parâmetros da água estão interligados, esse fator pode ter ocasionado alteração em outros parâmetros analisados e prejudicado o ganho de peso e crescimento dos peixes. 0 nível preconizado de oxigênio dissolvido na produção de tilápias é acima de 4 mg/L (PEREIRA; SILVA, 2012). Este dado é alarmante, pois colocam os peixes em uma situação de estresse que reduz seu desempenho e imunidade, predispondo-0s a agentes patogênicos. Diversos fatores ambientais (altitude, luminosidade, ventos, chuvas) e da produção (densidade de estocagem, taxa de alimentação, qualidade do alimento) se combinam para determinar a concentração de oxigênio na água (KUBITZA, 2017). No mês de fevereiro em todos os lotes amostrados, a maior concentração de oxigênio dissolvido não superou $0,4 \mathrm{mg} / \mathrm{L}$ e em dois lotes amostrados (5 e 6) chegou a 0,0 mg/L. A explicação encontrada para este fator estar extremamente baixo, ao mesmo tempo em todos os lotes amostrados, foi a presença da forte chuva no dia anterior à biometria. Apesar da tilápia ser extremamente tolerante a baixas concentrações de oxigênio dissolvido, suportando níveis próximos a 0 por várias horas, sem mortalidade, esta exposição prejudica 0 crescimento e conversão alimentar (KUBITZA, 2017). Conforme afirma Kubitza (1998), as águas provenientes de minas (originária de lençóis freáticos) apresentam baixa concentração de oxigênio dissolvido e altos níveis de gás carbônico. Foi observada a construção de viveiros em local de mina, sendo a única fonte de abastecimento de água. Esta informação, juntamente com outros dados, confirma o porquê de os valores de oxigênio dissolvido serem tão baixos no local de amostragem 5, decrescendo ao longo dos meses com o crescimento dos peixes, o que favorece ainda mais este declínio pelo maior consumo de oxigênio.

Em relação à turbidez, foram verificados, na maioria dos produtores, valores médios acima do recomendado para piscicultura de 25 a 50 FNU (Unidade Nefelométricas de Formazina) (QUEIROZ; SILVEIRA, 2006). Apenas no local de amostragem $P$, a turbidez se manteve adequada (40-48 FNU). A turbidez elevada é causada pelo excesso de partículas em suspensão, desta forma, a luz solar tem maior dificuldade de penetrar na água. Observando as Tabelas 1 e 2, foi possível relacionar a área do viveiro com os valores de turbidez, sendo que quanto maior a área do viveiro, mais próximos do recomendado estiveram esses valores. 0 fitoplâncton geralmente é a maior fonte de turbidez em criações de peixes, sendo que técnicas de manejo, como 0 arraçoamento, podem potencializar 0 crescimento de algas, diminuindo assim a penetração de luz no sistema (MERCANTE et al., 2006).

Foi averiguado que os viveiros 3 e 4 , atenderam 0 limite indicado por Timmons et al. (2002) de no máximo $25 \mathrm{mg} / \mathrm{l}$ de TDS (Total Dissolved Solids). Estes viveiros apresentaram, respectivamente, 23 e $24 \mathrm{mg} / \mathrm{L}$ 
de TDS. Já no lote 1, em nenhum momento foram observados valores adequados para TDS, estando sempre superiores ao indicado ( 36 a $58 \mathrm{mg} / \mathrm{L}$ ). Tal fato pode ser explicado pela superpopulação alojada neste viveiro $\left(9,8\right.$ peixes $\left./ \mathrm{m}^{2}\right)$ e 0 elevado fornecimento de ração diário $(420 \mathrm{~kg})$. 0 lote amostrado 2 foi 0 segundo com os maiores valores de TDS no viveiro ( 23 a $38 \mathrm{mg} / \mathrm{L}$ ) e esses resultados também estão relacionados com a grande quantidade de ração fornecida diariamente às tilápias (300 kg/dia no mês de outubro). Os viveiros 5 e 6 estiveram com valores de TDS acima do ideal, porém próximos a ele. A quantidade de sólidos totais dissolvidos aumentou gradativamente no decorrer de cada mês em todos os lotes amostrados.

A mensuração da condutividade elétrica possibilita saber a quantidade de íons presentes na água que permitem a passagem de eletricidade. A condutividade recomendada para piscicultura é 23 a 71 $(\mu \mathrm{S} / \mathrm{cm})$, segundo Sipaúba-Tavares (1994). Baseandose nestes valores, a condutividade está adequada para os lotes 4,5 e 6 . Porém os lotes 1 e 2 possuem valores acima do indicado por Sipaúba-Tavares (1994) que afirma que valores constantemente acima de $80 \mu \mathrm{S} /$ $\mathrm{cm}$ podem ser indicativos de elevada matéria orgânica em decomposição. Esta compreensão corrobora com 0 que foi dito anteriormente em sólidos totais, para a elevada quantidade de ração fornecida nestes dois viveiros. Em contrapartida, no local de amostragem 3, os valores da condutividade elétrica foram decrescendo ao decorrer dos meses, pois este lote foi vendido aos poucos (diretamente para o consumidor), diminuindo a densidade de estocagem e a quantidade de ração fornecida.

$\mathrm{Na}$ Tabela 3, observou-se que alguns parâmetros físico-químicos da água foram mais expressivos para a disparidade de tamanho, apresentando forte correlação, dentre eles: $\mathrm{pH}(0,7)$, turbidez $(0,9)$, TDS $(0,8)$ e condutividade elétrica $(0,8)$. $0 \mathrm{pH}$ também apresentou correlação moderada para a disparidade de peso $(0,6)$. Isto quer dizer que quanto mais próximo a 1,0, maior será a correlação entre duas variáveis (parâmetro ambiental $X$ disparidade de peso/tamanho), ou seja, a medida que uma variável aumenta a outra também se eleva. Neste estudo, ficou evidente que a turbidez é o parâmetro que mais gera disparidade de tamanho das tilápias, seguida por sólidos totais dissolvidos e condutividade elétrica. Já 0 pH é o parâmetro que mais comprometeu a disparidade de peso do lote.

Foi utilizado o valor médio dos parâmetros da água dos seis locais de amostragem juntamente. Este fato pode ter interferido para que 0 valor de oxigênio dissolvido não se correlacionasse com a disparidade de peso/tamanho, visto que na maior parte do tempo esteve abaixo do limite mínimo (4 mg/L).

\section{CONSIDERAÇÕES FINAIS}

É visível que os produtores de tilápia necessitam de assessoria periódica de um profissional qualificado e adquiram equipamentos básicos para monitoramento da qualidade da água. Outro entrave observado foi a presença de desovas, contribuindo negativamente para o desempenho do lote pelo consumo do oxigênio e alimentos dos peixes na engorda.

Vários fatores podem ter contribuído para aumentar a disparidade de peso e tamanho apresentadas neste estudo, dentre eles: densidade de peixes por viveiro, parâmetros físico-químicos da água alterados (oxigênio dissolvido, turbidez, TDS e condutividade elétrica) pelo manejo alimentar desregulado. Estas falhas de manejo interferiram diretamente no desenvolvimento dos peixes monitorados, em que alguns lotes demoraram 15 e 16 meses para serem abatidos.

\section{AGRADECIMENTOS}

Agradecemos aos tilapicultores por permitirem a realização desta pesquisa em suas propriedades; ao Rafael de Oliveira Cruz na coleta dos dados e à técnica Zélia S. S. Melato, do Laboratório de Análises Ambientais da PUCPR-Toledo, pela manutenção dos equipamentos e à Fundação Araucária, pela bolsa de PIBIC da D.D.Q. (Protocolo nº PP1736973/2018). 


\section{REFERÊNCIAS}

BALDISSEROTTO, B. Fisiologia de peixes aplicada à piscicultura. 3. ed. Santa Maria: UFSM, 2013. P. 239-240.

CHIDICHIMA, A. C. Industrialização de tilápias: agregação de valor para uma cadeia emergente da agricultura familiar. 2014. Dissertação (Mestrado em Desenvolvimento Rural Sustentável) - Universidade Estadual do Oeste do Paraná, 2014. Disponível em: http://tede.unioeste.br/bitstream/ tede/1488/1/Antonio_Chidichima_2014.Acesso em: 30 jul. 2019.

CONAMA. Conselho Nacional do Meio Ambiente. Resolução n 357, de 17 de março de 2005. Publicada no DOU nº 053, de 18/03/2005, págs. 5863. Disponível em: http://www2.mma.gov.br/port/ conama/legiabre.cfm?codlegi=459. Acesso em: 31 mai. 2019.

FURUYA, W.M. Redução do impacto ambiental por meio da ração. In: SEMINÁRIO DE AVES E SUÍNOS AVESUI; SEMINÁRIO DE AQUICULTURA, MARICULTURA E PESCA, 7., Belo Horizonte. Anais [...]. Belo Horizonte, 2007.

HEIN, G; BRIANESE, R. H. Modelo Emater de produção de tilápia. Toledo: Emater, 2004. Disponível em: http://www.emater.pr.gov.br/arquivos/ File/Biblioteca_Virtual/Premio_Extensao_Rural/1_ Premio_ER/ModeloEmaterProd_Tilapia.pdf. Acesso em: 28 maio 2019.

HEIN, G.; PARIZOTTO, M.L.V.; BRIANESE, R.H. Referência modular para o Oeste do Paraná: agricultor familiar, semi-intensivo, tanques escavados, clima Cfa. Toledo, 2004. Disponível em: http://www.iapar.br/arquivos/File/zip_pdf/ redereferencia/pp_modoeste.pdf. Acesso em: 04 jun. 2019.

JAUNCEY, K. The effects of varying dietary protein level on the growth, food conversion, protein utilization and body composition of juvenile tilapias. Aquaculture, Amsterdam, 1982.
KUBITZA; F. A água na aquicultura: Parte I. Panorama da Aqüicultura, v. 27, n. 162, jul./ago. 2017. Disponível em: http://www.acquaimagem.com.br/ docs/Panorama_162_Kubitza_agua_parte1.pdf. Acesso em: 23 set. 2019.

KUBITZA; F. A água na aquicultura: Parte II. Panorama da Aqüicultura, v. 27, n. 163, set./out. 2017. Disponível em: http://www.acquaimagem.com.br/ docs/Panorama_163_Kubitza_agua_parte2.pdf. Acesso em: 23 set. 2019.

KUBITZA, F. Produção de tilápias em tanques de terra estratégias avançadas no manejo. Panorama da Aqüicultura, v.19, n. 115, set./out. 2009. Disponível em: http://www.acquaimagem.com.br/ docs/Pan115_Kubitza.pdf. Acesso em: 01 jun. 2019.

KUBITZA, F; KUBITZA, L. M. M. Panorama da Aqüicultura, v. 10, n. 59, maio/jun. 2000. Disponível em: http://www.matsuda.com.br/matsuda/upload/ artigostecnicos/qualidade_da_agua_sistemas_ de_cultivo_planejamento_da_producao_manejo_ nutricional_e_alimentar_e_sanidade.pdf. Acesso em: 27 mai. 2019.

KUBITZA; F. Qualidade da Água na Produção de Peixes: Parte I. Panorama da Aqüicultura, v. 8, n. 45, 1998. Disponível em: http://www.acquaimagem.com. br/docs/Pan45_Kubitza.pdf. Acesso em: 01 jun. 2019.

LIMA, A. F.; SILVA, A. P.; RODRIGUES, A. P. 0.; BERGAMIN, G. T.; TORATI, L. S.; PEDROZA FILHO, M. X.; MACIEL, P. O. Qualidade da água: piscicultura familiar. Palmas: Embrapa Pesca e Aquicultura, 2013. 8p. Disponível em: https://www.infoteca.cnptia. embrapa.br/infoteca/handle/doc/972064. Acesso em: 27 jul. 2019.

MARENGONI, N. G; BUENO, G. W; GONÇALVES JÚNIOR, A. C; OLIVEIRA, A. A.M. de A. Desempenho produtivo e viabilidade econômica de juvenis de tilápia-do-Nilo cultivados na região oeste do Paraná sob diferentes densidades de estocagem. Rev. Bras. Saúde Prod. An., v. 9, n. 2, p. 341-349, abr./jun. 2008. Disponível em: http://revistas.ufba.br/index.php/rbspa/article/ viewArticle/917. Acesso em: 31 mai. 2019. 
MATA, D. A. da; SOUZA T.; GOMES C. M.; ANDRADE R. A. de; APOLINÁRIO M. de 0. Limnologia e sua Correlação com a Produtividade da Tilápia Oreochromis niloticus. Agropecuária Científica no Semiárido, v. 14, n. 3, p. 254-265, 2018. Disponível em: http://revistas.ufcg.edu.br/acsa/index.php/ACSA/ article/view/1053. Acesso em: 27 jul. 2019.

MERCANTE, C.T.J.; SILVA, D.; COSTA, S.V. Avaliação da qualidade da água de pesqueiros da região metropolitana de São Paulo por meio do de varáveis abióticas e clorofila. In: ESTEVES, K.E. e SANT'ANNA, C.L. Pesqueiros sob uma visão integrada de meio ambiente, saúde pública e manejo. São Paulo, 2006.

OLIVEIRA, E. G. de; SANTOS; F. J. de S. dos; PEREIRA, Al. M. L; LIMA, C. B. Produção de tilápia: mercado, espécie, biologia e recria. Teresina: Embrapa MeioNorte, 2007. Disponível em: https://www.infoteca.cnptia.embrapa.br/bitstream/ doc/69806/1/Circular45.pdf. Acesso em: 28 mai. 2019.

PEIXE BR. Associação Brasileira da Piscicultura.

Anuário 2019 Peixe BR da Piscicultura. São Paulo, 2019. Disponível em: https://www.peixebr.com.br/ Anuario2019/AnuarioPeixeBR2019.pdf. Acesso em: 19 set. 2019.

PEREIRA, A. C.; SILVA, R. F. Produção de tilápias. Niterói: Rio Rural, 2012. (Manual técnico 31). Disponível em: http://www. microbacias.rj.gov.br/conteudo/compartilhados/ pesquisa_participativa_apoio_tecnico/31\%20 \%20Produ\%C3\%A7\%C3\%A30\%20de $\% 20$

Til\%C3\%A1pias.pdf. Acesso em: 28 mai. 2019.

QUEIR0Z, J. F. de; SILVEIRA, M. P. Recomendações práticas para melhorar a qualidade da água e dos efluentes dos viveiros de aquicultura. Jaguariúna: Embrapa, 2006. (Circular técnica 12). Disponível em: http://www.cnpma.embrapa.br/aquisys/circular12. pdf. Acesso em: 28 mai. 2019.

RODRIGUES, P. de T. R. Manual de qualidade da água para aquicultura. Texto adaptado por Léo de Oliveira. Preserve, 1995. Disponível em https:// www.embrapa.br/documents/1354377/1743436/ Manual+Qualidade $+\%$ C3\%81 gua+Aquicultura. pdf/674c0a9a-2844-43e2-946204fddd387529?version=1.0. Acesso em: 28 mai. 2019.

SANTOS, V. B. dos. Crescimento morfométrico e alométrico de linhagens de Tilápia (Oreochromis niloticus). 2004. Dissertação (Mestrado em Zootecnia) - Lavras: Universidade Federal de Lavras, 2004. Disponível em: http://repositorio.ufla.br/ bitstream $/ 1 / 3882 / 1 /$ DISSERTA\%C3 $\% 87 \%$ C3 $\% 830$ Crescimento\%20morfom $\%$ C3\%A9trico $\% 20 \mathrm{e} \% 20$ alom $\%$ C3\%A9trico\%20de $\% 20$ linhagens $\% 20$ til\%C3\%A1 pia\%20(\%200reochromisniloticus).pdf. Acesso em: 30 jul. 2019.

SIPAÚBA-TAVARES, L.H. Limnologia aplicada à aqüicultura. São Paulo: FUNEP, 1994.

TIMMONS; M. B. et al. Recirculating aquaculture systems. 2. ed. Ithaca, NY: Cayuga Aqua Ventures, 2002.
Recebido em: 30/07/2019

Aceito em: 27/09/2019 